\title{
Qualificando o cuidado à criança na Atenção Primária de Saúde
}

\author{
Qualifying child care in Primary Health Care \\ Calificando el cuidado a los niños en Atención Primaria de Salud
}

\section{Francisca Georgina Macedo de Sousa', Alacoque Lorenzini Erdmann"}

' Universidade Federal do Maranhão, Curso de Graduação em Enfermagem, Mestrado Acadêmico em Enfermagem, Grupo de Estudo e Pesquisa em Saúde da Família, da Criança e do Adolescente (Coordenadora). São Luís-MA, Brasil.

"Universidade Federal de Santa Catarina, Programa de Pós-Graduação em Enfermagem, Grupo de Estudos e Pesquisas em Administração, Gerência do Cuidado e Gestão Educacional em Enfermagem e Saúde (Coordenadora). Pesquisadora do CNPq Florianópolis-SC, Brasil.

Submissão: 20-11-2011 Aprovação: 26-11-2012

\section{RESUMO}

O cuidado à criança sustenta-se em um agir compartilhado, enriquecido por subjetividades de profissionais e família, com objetivo de atender às características peculiares do crescimento e do desenvolvimento infantil. Este estudo teve como objetivo compreender modos de cuidar e de cuidado à criança na Atenção Primária de Saúde, com base na Grounded Theory. Participaram da investigação 29 sujeitos entre gestores, coordenadores de serviços e de cursos de enfermagem e medicina, enfermeiros, médicos e mães de crianças atendidas pela Estratégia Saúde da Família em São Luís - MA. A entrevista semiestruturada foi utilizada para a coleta de dados. A categoria Qualificando o cuidado à criança na Atenção Primária de Saúde e suas subcategorias reconhecem que cuidar tem diferentes sentidos que se fundam no valor da vida e na dignidade humana e que o cuidado se constrói a partir de esforços, colaboração, comunicação, complementaridade e no fazer/agir de profissionais, famílias, serviços e gestores.

Descritores: Enfermagem; Enfermagem em Saúde Comunitária; Cuidado da Criança.

\section{ABSTRACT}

Child care is supported by a shared action enriched by subjectivities of professionals and family in order to meet peculiar characteristics of child growth and development. This study aimed to understand modes of child care in Primary Health Care, supported by the Grounded Theory. Twenty-nine subjects participated in the research, including managers, coordinators of nursing and medicine courses, doctors, nurses and mothers of children assisted by the Family Health Strategy in São Luís-MA, Brazil. To collect data it was used a semi-structured interview. The category Qualifying child care at PHC and its respective subcategories recognize that care has different meanings based on the value of life and human dignity and that the value of care is built by efforts, collaboration, communication, complementarity and in the actions of professionals, families, services and managers.

Key words: Nursing; Community Health Nursing; Care for Children.

\section{RESUMEN}

El cuidado a los niños debe estar sostenido en un acto compartido enriquecido por las subjetividades de profesionales y familia con el objetivo de atender a las características propias del crecimiento y desarrollo infantil. El objetivo de este estudio fue comprender las maneras de cuidado a los niños en la Atención Primaria de Salud apoyado en la Grounded Theoory. Participaron de la investigación 29 sujetos entre gerentes, coordinadores de servicios y de cursos de enfermería y medicina, enfermeros y médicos y madres de los niños atendidos por la Estrategia del Salud del Familia en el municipio de São Luís MA. Para la colecta de datos fue utilizada la entrevista semiestructurada. La categoría Calificando el cuidado a los niños en la Atención Primaria de Salud y sus respectivas subcategorías reconocen que cuidar tiene sentidos diferentes que se fundan en el valor de la vida e en la dignidad humana y que el valor al cuidado se construye en los esfuerzos, en la colaboración, en la comunicación, en la complementariedad y en el hacer/actuar de profesionales, familias, servicios y gerentes.

Palabras clave: Enfermería; Enfermería en Salud Comunitaria; Cuidado del Niño.

Extraído da Tese de Doutoramento "Tecendo a teia do cuidado à criança na Atenção Básica de Saúde: dos seus contornos ao encontro com a integralidade", apresentada, em 2008, ao Programa de Pós-Graduação em Enfermagem, da Universidade Federal de Santa Catarina. Florianópolis-SC, Brasil. 


\section{INTRODUÇÃO}

O cuidado à criança, ou a qualquer outra fase do ciclo vital humano, é complexo, multidimensional e sofre influência de diversos e distintos fenômenos nas ações do cuidar. $\mathrm{O}$ cuidado apresenta-se, como um conjunto de circunstâncias interdependentes, que resulta em um uma conjugação de elementos que confluem para um todo complexo que se constrói e se modifica continuamente ${ }^{(1)}$. Por conseguinte, a integralidade, como princípio da política de saúde, remete para a compreensão de que os fatores que interferem na saúde da criança são amplos e perpassam por outros setores que não só o da saúde.

O Programa de Atenção Integral à Saúde da Criança (PAISC) tem como proposta, além da organização dos serviços, a organização de um processo de abordagem que envolve toda uma rede de instituições e serviços de forma a obter impacto epidemiológico sobre determinadas circunstâncias do processo de viver da criança. É uma proposta que exige que profissionais, equipe, instituição e unidades de saúde se organizem como um todo, implicando na atuação multi, inter e transdisciplinar. Trata-se, portanto, de um fazer/pensar integrado de todo o serviço e de toda a equipe e não da tarefa de um profissional ou de uma categoria isoladamente. O sentido da integralidade do cuidado é muito mais que um procedimento, uma ação, uma conduta terapêutica/assistencial realizada por um profissional de saúde. Na perspectiva da integralidade, o cuidado tem o sentido de "atitude cuidadora que envolve o assistir ou o tratar segundo os parâmetros do acolher e do

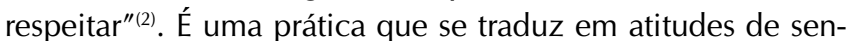
sibilidade, confiança, pertencimento, tratamento digno, horizontalidade e continuidade da atenção.

Por outro lado, a abordagem na saúde se constitui em espaço de intervenção de sujeitos que podem exercer o seu trabaIho conforme seus modos de compreender e atribuir sentidos ao seu fazer, ao seu agir, pois, em um sistema de saúde os profissionais produzem modos diferentes de cuidado e de cuidar que também são percebidos de diferentes maneiras por quem é cuidado. Portanto, os modos de cuidar e de produzir cuidados vão se delineando e sendo percebidos por quem produz e por quem os recebe. Nessa perspectiva questiona-se: Como é caracterizado o cuidado à criança na atenção primária para profissionais da Estratégia Saúde da Família, gestores, docentes e mães? Objetivou-se, pois, compreender modos de cuidar e de cuidado à criança na Atenção Primária de Saúde.

\section{METODOLOGIA}

Estudo qualitativo, apoiado nos pressupostos da Grounded Theory ${ }^{(3)}$. Foram sujeitos da pesquisa gestores estaduais e municipais de saúde, enfermeiros e médicos da Estratégia Saúde da Família, docentes dos cursos de graduação e pós-graduação de Enfermagem e Medicina, coordenadores de serviços da área da criança e mães de crianças menores de cinco anos cadastradas e atendidas pela Saúde da Família no município de São Luís, capital do estado do Maranhão, situado na região nordeste do Brasil. A coleta e análise dos dados foi guiado pela amostragem teórica, que consistiu em decidir quais dados coletar e onde encontrá-los para assim reunir dados sobre o mesmo evento ou fenômeno e entrevistar múltiplos atores. Portanto, o objetivo da amostragem teórica é permitir ao investigador buscar "locais, pessoas ou fatos que maximizem oportunidades de descobrir variações entre conceitos e de tornar densas categorias em temos de suas propriedades e de suas dimensões"(4). Em síntese, o investigador decide, com base em seus próprios dados, que informação coletar e onde encontrá-las.

Por compreender que o objeto investigado encontra-se situado sob três grandes dimensões: da política de saúde, da organização do sistema de saúde e da organização das práticas de cuidado, procuramos buscar, nestas três dimensões, os participantes da investigação, que representassem melhores possibilidades para a compreensão da integralidade do cuidado à criança na Atenção Primária de Saúde. Assim, para o primeiro grupo amostral, centramos a investigação na primeira e segunda dimensão sendo sujeitos de pesquisa o gestor estadual e municipal, os coordenadores e chefes de serviços da Atenção Primária de Saúde totalizando sete participantes.

Participaram do segundo grupo amostral os profissionais que, no período da coleta, exerciam função de coordenadores de curso de graduação (Enfermagem e Medicina); coordenadores de curso de pós-graduação (Especialização em Saúde da Família e Mestrado em Saúde da Mulher e da Criança) e docentes totalizando seis participantes. O terceiro grupo amostral envolveu sete profissionais da Estratégia Saúde da Família (05 enfermeiros e 02 médicos). Cabe relatar que, para este grupo, foram definidos alguns critérios de inclusão: ser Unidade Saúde da Família, estar com a equipe completa e os profissionais terem vínculo definido por concurso público e em exercício profissional por pelos menos um ano. O quarto grupo amostral foi constituído por cinco médicos da Estratégia Saúde da Família, para os quais foram estabelecidos os mesmos critérios do grupo anterior. O quinto grupo amostral foi composto por quatro mães, cujas famílias eram cadastradas na Estratégia Saúde da Família e as crianças acompanhadas pela equipe de saúde. Participaram, portanto, 29 sujeitos entre profissionais de saúde, gestores, docentes e mães.

A coleta de dados foi realizada com o recurso da entrevista semiestruturada realizada nos locais de trabalho dos participantes, em data e horário por eles definidos. O encontro com as mães para a entrevista aconteceu antes ou depois do atendimento de enfermagem ou médico de seus filhos na própria unidade de saúde.

Buscando alcançar o objetivo proposto na investigação as entrevistas foram conduzidas por diversos questionamentos que se diferenciaram segundo as hipóteses e o grupo amostral. Para o primeiro grupo foi perguntado: Como os profissionais de saúde centram seus atos de cuidado à criança? No segundo e terceiro grupo as perguntas foram as seguintes: Como acontece o cuidado à criança na sua equipe de trabalho? Que escolhas você faz para cuidar da criança? A partir das categorias e das relações entre elas, foi elaborada a seguinte pergunta de pesquisa para o quarto grupo amostral, constituído somente por médicos: Como os médicos se posicionam frente ao trabalho no PSF e às demandas do cuidado à criança? De que forma você contribui para o cuidado à criança? Buscamos no 
quinto grupo amostral maior densidade das categorias. Participaram desse grupo cinco mães que foram assim questionadas: $\mathrm{O}$ que você pensa sobre o cuidado à criança no PSF? O que você deseja para o cuidado dos seus filhos no PSF?

O projeto de pesquisa foi aprovado pelo Comitê de Ética do Hospital Universitário, da Universidade Federal do Maranhão (HU-UFMA), sob o Registro no 254/06 e Processo $n^{\circ}$. 33104-850/2006. Nas falas dos participantes optamos por identificá-las por nomes próprios, mas que não são os verdadeiros nomes dos participantes. Seguindo os critérios éticos, definidos na Resolução 196/96 do Conselho Nacional de Saúde nos preocupamos em somente iniciar a coleta de dados após o parecer formal do Comitê de Ética e da autorização da Secretaria Municipal de Saúde. A adesão, dos participantes à investigação foi voluntária, independente de qualquer benefício ou constrangimento. A coleta dos dados foi posterior aos esclarecimentos sobre os objetivos do estudo e da leitura e assinatura do Termo de Consentimento Livre e Esclarecido. Foi garantido aos participantes o acesso às pesquisadoras para quaisquer esclarecimentos, assim como o desligamento dos mesmos a qualquer momento do processo da investigação; mantivemos em sigilo o nome de todos os participantes atribuindo codinomes.

\section{RESULTADOS}

Cuidar da criança relaciona-se às práticas dos trabalhadores de saúde, no sentido de que esses sejam capazes, em um diálogo recursivo, gerar acolhimento, vínculo e responsabilização em um esforço, para desfragmentar o atendimento e gerar um legítimo encontro com o outro, no nosso caso, criança e família. No entanto, não existe um sentido comum sobre o que seria o melhor para as diversas maneiras de agir, de cuidar. $\mathrm{O}$ que podemos interrogar são os valores que atribuímos ao nosso agir. Pois são os valores que determinam e revelam os nossos compromissos e responsabilidades para com o outro. Assim, o conceito Qualificando o cuidado à criança diz respeito à nossa essência como profissionais da saúde. Diz respeito às nossas opções e desejos, às nossas escolhas. Do ponto de vista dos participantes da investigação o cuidado se manifesta nos modos de cuidar que se conformou no processo de análise dos dados em cinco subcategorias: Vendo o Cuidado Diferente; Falando do Cuidado Desigual; Comentando sobre o Cuidado "Invisível"; Caracterizando o Cuidado Integral e Atribuindo Valores ao Cuidado.

A subcategoria Vendo o cuidado diferente indica uma maneira de ser e de se ocupar de alguém ${ }^{(5-6)}$, tendo em consideração as suas necessidades, os seus desejos. Dá a ideia de conhecer, dedicar atenção particular. Enquanto que, Falando do cuidado desigual, significa fazer julgamentos à mãe assim como as dificuldades de acesso aos serviços de saúde. Estas duas subcategorias colocam-se entre as dimensões do cuidado percebidas pelos participantes e expressas nas suas falas:

Eu aqui (na Unidade de Saúde) me sinto em casa, todo mundo me conhece, sabem onde eu moro, como é que eu vivo. Conhecem meus filhos, meu marido, todo mundo, as pessoas sabem quem eu sou, e quem meu filho é. Eu sinto a diferença quando eu vou para outro hospital, para outro posto porque lá ninguém me conhece e a gente é uma pessoa estranha. Gosto daqui por causa disso. Lá eu não sei o nome deles (profissionais) e eles não sabem o meu. É diferente. Lá no hospital eles acham que a culpa do filho da gente adoecer é da mãe. Elas dizem que se o menino está assim é porque a gente não leva no médico... dizem essas coisas assim. (Emilia)..

Eu vejo que no PSF existem duas coisas que são importantes em relação ao cuidado a criança. Uma é que nós identificamos nas visitas domiciliares que as mães cuidam, apesar de todas as dificuldades, e isso afasta aqueles julgamentos que às vezes nós fazemos quando não conhecemos. E outra coisa é que as mães percebem que estamos interessadas na saúde dela e dos filhos. Isso faz do cuidado aqui ser diferente. (Camila).

Aqui é assim, se eu venho da feira e vejo o carro da doutora na porta, eu já entro, já falo com ela, com as pessoas, se tiver sentindo alguma coisa, eu já falo, é bom porque a gente pode fazer isso. E eles falam, só se eles estiverem muito ocupado, que aí não pode mesmo. Eu só faço isso aqui porque todo mundo me conhece. Outro dia eu levei meu filho pra consultar com uma médica neurologista, e quando chegou a vez dele a moça chamava o nome dele bem alto e eu tava bem pertinho, mas como ela não conhecia ela gritava. Aqui (ESF) não precisa chamar assim porque eles me conhecem e sabem quem é meu filho. Aqui eles (profissionais) conversam comigo, diz o jeito de fazer as coisas direitinho. Em outro hospital eles nem falam com a gente, tratam mal as pessoas. É muito diferente daqui. (Elisa).

[...] O PSF ajuda muito porque permite olhar a criança de uma maneira mais completa, até pela proximidade com a casa e pela convivência da equipe com a família. Isso faz a diferença. $E$ aí as famílias passam a nos enxergar como amigos, não só como profissional que só ajuda na hora da doença. Tanto que muitas pessoas vêm aqui no Posto pra conversar problemas pessoais com a gente. (Camila).

Eu consigo marcar uma consulta quando um dos meus fiIhos precisa, mas quando é problema de doença mesmo tudo fica mais difícil, porque não tem vaga nos hospitais e a gente fica correndo de um lado pro outro sem saber o que fazer. As pessoas não querem nem saber, não tem pena da gente, nem dos filhos da gente. Aqui no posto é diferente. Outro dia a enfermeira e a médica ficaram comigo aqui até quase de noite porque a febre dele não baixava, elas ficaram comigo, conversaram comigo, arranjaram remédio. (Elisabete).

As falas parecem colocar em evidência que o cuidar tem uma intenção que é a de reparar, a de aliviar, a de satisfazer, a de educar, a de informar. Cuidar tem a ver com o fazer o que 
é bom (cuidado diferente). Então existe o cuidar mal? Cuidar mal (cuidado desigual) não é a negação da ação de cuidar, mas a sua inadequação ${ }^{(6)}$. Para o autor ${ }^{(6)}$, apesar de haver a preocupação e a ocupação do cuidado, a ação não é boa e para esclarecer descreve algumas situações: a primeira é a diferença entre tomar cuidado e prestar cuidado. Tomar cuidado é no sentido de dedicar uma atenção particular à pessoa em uma situação particular com o objetivo de promover a sua saúde (cuidado diferente). Prestar cuidados parece limitar-se aos atos que requerem um saber fazer baseado em conhecimentos e técnicas precisas (cuidado desigual) e tem o sentido de "fazer o que se sabe fazer para tratar uma doença tendo em vista a sua cura"(6). Portanto, Vendo o cuidado diferente e Falando do cuidado desigual foi revelado como tensões entre os níveis do sistema de saúde - APS e hospital -, por exemplo. Refletiram que aspectos significativos do sistema de saúde baseados na equidade ficam à sombra em um funcionamento desigual dos cuidados de saúde à criança. $O$ cuidado desigual é atribuído também ao momento em que as dimensões relacionais se afastam das relações de cuidado. Valoriza mais o saber técnico e as regras institucionais do que as atitudes de escuta e acoIhimento no momento do encontro para a produção do cuidado. O "diálogo e a escuta foi colocada em segundo plano para dar lugar a um processo centrado nas regras instituídas como se fosse um fim em si mesmo"(7). Por outro lado, a forma de organização da ESF favorece a quebra de certas hegemonias na saúde, facilita o processo de interação entre profissionais e famílias/comunidade gerando horizontalidade nas relações, o que pode fazer com que as mães sintam-se mais a vontade para falar dos seus problemas e das suas dificuldades.

A terceira subcategoria Comentando sobre o Cuidado "Invisível" manifesta-se em pequenas atitudes, gestos, atos do cotidiano, em especial, realizados pela enfermeira:

Eu acho que o cuidado não precisa ser uma grande coisa, tem essas coisas pequenas que tem um valor imenso. Aqui no Posto na nossa relação com as mães isso acontece diariamente. E são coisas que nós fazemos que não é quantificado, não tem como eu registrar na produtividade e fica assim como um cuidado invisível. Quando eu vou fazer a produtividade, aquilo que realmente a enfermagem faz de cuidado, não tem como registrar e a gente tem a sensação de que não fizemos nada apesar do dia ter passado e a gente não ter parado. Então eu acho que é um sistema que não serve para o cuidado da enfermagem. Não sei se a preocupação é com o cuidado ou se o que eles querem é a produtividade, é o número. (Carla).

O deslocamento das atividades da Saúde da Família para a produção de procedimentos entre outras limitações impõe um agir isolado dos profissionais. No que tange às práticas, esse sistema de registro, exclui o cuidado como prática do enfermeiro nas atividades diárias de atenção à criança e é caracterizado como "cuidado invisível". As ações são realizadas, mas dado o caráter subjetivo do cuidado, o enfermeiro não encontra formas de registro no sistema disponível nas Unidades de Saúde da Família.
O Sistema de Informação da Atenção Básica - SIAB(8) foi desenvolvido como instrumento de gestão da saúde pelo Ministério da Saúde e tem sofrido algumas alterações sem, no entanto, contemplar as práticas de enfermagem em saúde coletiva. Por meio do SIAB são obtidas informações sobre cadastro das famílias, condições de moradia e saneamento, situação de saúde, produção e composição das equipes de saúde. O SIAB é para o Ministério da Saúde o principal instrumento de monitoramento das ações com o objetivo de fornecer informações que subsidiem a tomada de decisão pelos gestores e a instrumentalização pelas instâncias de Controle Social, tornando públicos os dados para uso de todos os atores envolvidos na consolidação do SUS. São informações epidemiológicas que visam também o financiamento da saúde no município. Não há no município de São Luís - MA, um sistema de registro de práticas de enfermagem na APS. No SIAB são registrados procedimentos quantificáveis. No entanto, definir e registrar a prática de enfermagem é uma necessidade - deveria ser uma prioridade -, utilizando uma linguagem especifica da profissão. Vale ressaltar que desde a década de noventa existe uma mobilização mundial para a sistematização da linguagem específica da enfermagem. No Brasil, a Associação Brasileira de Enfermagem (ABEn) tem se articulado e envidado esforços para a consolidação da Classificação Internacional para a Prática de Enfermagem - CIPE. Em 1996 foi publicada a versão alfa da CIPE seguida em 1999 pela publicação da versão beta e em 2002 pela versão beta 2. Os objetivos da CIPE, entre outros, é identificar um vocabulário especial e desenvolver um sistema de classificação dos componentes da prática de enfermagem de modo a sistematizar uma linguagem específica que descreva essa prática ${ }^{(9)}$. Além da CIPE, a ABEn desenvolveu a Classificação Internacional das Práticas de Enfermagem em Saúde Coletiva (CIPESC) com a finalidade de revelar a dimensão, diversidade e amplitude das práticas de enfermagem no contexto do SUS, visando um sistema de classificação da prática de enfermagem em saúde coletiva. A CIPESC, entre outras questões, tem como proposta dar visibilidade às ações de enfermagem no âmbito nacional e internacional.

A quarta subcategoria, Caracterizando o cuidado integral significa tomar a criança como totalidade envolvendo referenciais com os quais os profissionais se confrontam subsidiando alternativas e encaminhamentos para a saúde infantil. Os esforços são dirigidos para o agir profissional sustentado no vínculo e na aproximação da equipe com a família, com a criança e com a comunidade, capazes de assegurar o desenvolvimento de responsabilidades e de modificar o processo e as relações de trabalho. Os diferentes modos de cuidar e de cuidado acompanham o movimento no qual o cuidado integral é entendido pelos participantes da investigação a partir de quatro dimensões: como a abertura dos profissionais para atender outras necessidades que não as diretamente ligadas à doença; o cuidado integral como direito da criança; o cuidado como dimensão humana e o cuidado integral como acesso a todos os níveis da assistência:

[...] cuidado integral são os muitos olhares e olhares amplos, pois a integralidade vai além da queixa clínica que a criança 
apresenta. Esse momento de encontro com a criança e a mãe ou a família por motivo de doença deve ser enriquecido por esse olhar mais amplo, um momento para olhar a criança como um todo, independente da queixa. (Alice).

[...] integralidade é a visão o todo. Nesse caso a criança é vista por inteiro, como um sujeito de direitos. Uma criança que chega no serviço para um atendimento específico, precisa ser observada em todos os outros aspectos, por exemplo, veio consultar por uma otite, mas é possível avaliar a vacina, o crescimento, o desenvolvimento, porque não aproveitar essas oportunidades? São estas oportunidades perdidas que precisam ser recuperadas para o atendimento integral. É a oportunidade para que os diversos aspectos sejam vistos: promoção, proteção, assistência e sempre com vistas a continuidade do cuidado. Integralidade é o direito da criança a um fluxo que permita acesso aos serviços de média e alta complexidade. Integralidade é essa rede articulada para responder às necessidades da criança e de suas famílias. É a integração das ações básicas com as de média e alta complexidade. (Bianca).

[...] na saúde da criança a integralidade exige um conceito mais abrangente, porque envolve a criança, o seu cuidador e sua família. No cuidado à criança o profissional sempre deve ter a referência do cuidador e da família dentro do seu contexto social. (Carmen).

[...] integralidade tem a ver com resolutividade do serviço. A resolutividade tem a ver com a questão do ser humano. Porque muitas vezes a gente consegue resolver alguma situação de doença, mas não tem aquele estalo de olhar o outro como ser humano. Isso vai muito mais além, de olhar e enxergar o todo, de olhar o outro como ser humano. (Camila).

[...] Integralidade é ouvir, é assistir, é acompanhar, é compreender o outro em todos os aspectos e dimensões. Então uma das coisas importantes para a integralidade são as parcerias com a equipe, com os agentes, com as famílias, com a escola e com a rede. (Cecília).

A categoria Caracterizando o cuidado integral pede por uma ação política de sujeitos individuais e coletivos numa combinação de saberes e técnicas para atender as necessidades de crescimento e desenvolvimento da criança e não somente a doença; por uma articulação entre prevenção e assistência; por disponibilizar tecnologias de cuidado que envolva o atendimento individual, a família e a educação em saúde por meio de processos dinâmicos e participativos, atendimento domiciliar, visita domiciliar, ações de vigilância à saúde assim como todas aquelas que garantam o acolhimento.

O cuidado integral implica atender às necessidades da criança por meio de um sistema de cuidados organizados hierarquicamente, compreendido aqui, na dimensão do direito. $\mathrm{O}$ acesso a níveis de maior complexidade no sistema é uma dimensão importante da integralidade não sendo lícito negar os benefícios da tecnologia em saúde hoje disponíveis. Além do caráter completo do cuidado, a integralidade envolve a continuidade do cuidado $^{(10)}$. Estas questões dizem respeito à capacidade de resolutividade não somente do PSF, mas do sistema de saúde como um todo.

Caracterizando o cuidado integral pode ser percebido nos modos de cuidar da criança por onde circulam afetos e emoções. Esse envolvimento e preocupação com o outro permitem conceber práticas de cuidado integral à criança. Assim a integralidade do cuidado à criança ganha cada vez mais centralidade nos modos e atitudes de cuidado pelos profissionais de saúde em conexões desencadeadas pela mobilização de atitudes subjetivas e nas escolhas de gestores e profissionais. Mas, não existe um sentido comum sobre o que seria o melhor para as diversas maneiras de agir. Da mesma forma que não se pode esperar da totalidade de profissionais a mesma dimensão do cuidado. Mas podemos pensar que sentido tem o cuidado para cada um de nós, interrogando os valores aos quais ele se refere, pois embora a humanidade sinta as mesmas necessidades, a maneira de satisfazê-las depende de inúmeros valores e a percepção do cuidado a cerca de si mesmo, influi na capacidade de desempenhar a função do cuidar. Assim a subcategoria Atribuindo Valores ao Cuidado, dá a ideia de fazer escolhas e nos remete a valorização da condição humana; qualifica o cuidar e amplia o olhar do profissional. Nesse olhar as enfermeiras sentem necessidade de apoiar seus conhecimentos em outras disciplinas e com outros profissionais:

Sinto necessidade de ter aqui na unidade uma assistente social, um psicólogo, um fisioterapeuta, porque o meu conhecimento de enfermeira é pequeno se comparado com os problemas que as famílias trazem para cá. Eu acho que um trabalho com outros profissionais e com outros conhecimentos é fundamental (Camila).

Cuidar da criança é ser pedagogo, psicólogo, professor, porque trabalhamos com a criança, com a mãe, com a família de uma maneira maior, ensinando. E para eu ensinar eu preciso aprender mais. Aprender mais para cuidar meIhor (Célia).

Atribuindo Valores ao Cuidado é mostrar-se sensível com o problema do outro, com o sofrimento do outro. É emocionar-se:

O cuidado, só a palavra cuidado, por si só, significa sensibilidade. Eu preciso da sensibilidade para me incomodar com o sofrimento do outro. E misturar cuidado e criança, parece uma mistura perfeita que só acontece com sensibilidade. (Cecília).

Na pediatria cuidando das crianças é emoção permanente, sorrimos, choramos, vibramos, ficamos tristes, é tudo isso. [...] é emoção o tempo todo. (Darci).

Atribuindo Valores ao Cuidado caracteriza-se pela capacidade do profissional de comunicar-se com o outro (criança/ 
mãe/família) sem a atitude autoritária que muitas vezes ronda as relações de cuidar em saúde:

A criança surpreende [...]. Outro dia [...] atendendo a uma criança [...] estava explicando para a mãe como fazer a limpeza do couro cabeludo da criança (ele estava com escabiose). Ele (a criança) vira e diz assim: tia porque atua não fala comigo? Sou eu que lavo minha cabeça (foi mais ou menos assim) [...] eu desmontei [...] desde esse dia eu sempre falo para a criança [...] para a mãe ouvir. O foco mudou porque essa criança me advertiu. Eu procuro falar com calma, com palavras que ela possa compreender, brinco, mostro como fazer, peço para ela fazer. (Claudia).

A comunicação é a nossa maior ferramenta. Falar para esclarecer e não para complicar. Para orientar e não para assustar a mãe [...] falar com a mãe e a criança, porque posso falar usando a palavra, mas falo também com um afago, com um carinho, com o olhar. (Darci).

Somos seres de comunicação e, na saúde, não podemos pensar agir sem o processo de comunicação: "para ajudar", "para apoiar", "para esclarecer". É "ferramenta" para incorporar novos modos e novos comportamentos para cuidar e para o cuidado porque o cuidado não se materializa sem a humanização ${ }^{(11)}$. Nessa direção o cuidado está relacionado ao modo como os profissionais lidam com as crianças, com as mães e com as famílias exigindo adequada comunicação caracterizada como aquela que tenta diminuir conflitos para o alcance dos objetivos ${ }^{(12)}$. Essa condição nem sempre existe nas relações profissionais e institucionais com mães e crianças:

Eu fico chateada porque o pessoal daqui (da recepção) não fala direito com a gente. Elas não respondem direito. [...] a gente termina dizendo umas coisas, brigando não é? Ficando zangada. [...] os médicos não diz direito as coisas. Meu marido briga comigo porque ele diz que eu não sei dizer direito o que o menino tem [...] é porque eles (médicos) não explicam [...] a gente pergunta, mas eles (médicos) ficam calados. (Eliana).

A comunicação como valor foi também revelado nas queixas de profissionais e mães:

Os atendimentos de maneira geral são curtos porque tem a coisa da demanda e da produtividade. Apressamos o passo para atender todo mundo e isso compromete a comunicação e a qualidade. (Cecília).

Terminamos atendendo um número maior de crianças e consequentemente o tempo de cada atendimento é muito curto. Se por necessidade da mãe ou da criança ela fica mais tempo na consulta vamos ter que correr com as seguintes. (Denise).

[...] foi tão rápido que ele consultou que eu fiquei assim sem entender [...] não entendia nada. Sair de lá sem entender nada. (Elisa).
A pressa no atendimento se impõe como dificuldade para o cuidado à criança e para que o processo comunicativo se efetive. Os momentos de encontros das mães com os profissionais não podem se configurar como um encontro para buscar sintomas e queixas. Se assim o for, o cuidado nem sempre é eficaz, pois impede que a mãe se sinta à vontade para questionar e esclarecer dúvidas e necessidades. A comunicação, como valor, é percebida tanto por quem cuida como por quem é cuidado. É condição que exige repensar e reagir a favor da reintegração da ação do pensar na saúde. Sob essa dimensão, as experiências cotidianas constituem sua principal fonte de revalorização. A efetividade de comunicação relaciona-se com a linguagem corporal que se expressa pela proximidade, postura e contato visual com o outro ${ }^{(12)}$, envolve interação, processos sociais, psicológicos, pessoais e da própria organização do trabalho. Utilizar de forma inadequada a comunicação pode ser caracterizado como descuidado por fazer com que o modo de cuidar seja impessoal e descompromissado; reduz o universo do cuidado e dos saberes para um modo de cuidar estruturado, rígido, empobrecedor do encontro, onde crianças e mães são "não-sujeitos", simples cumpridores de determinações e rituais da saúde defendidos e operados pelos profissionais.

No cuidado à criança, o processo comunicativo deve estar atento aos valores, opiniões e crenças da família, respeitando e considerando as diferenças. Desse modo a cultura como valor do cuidado emergiu das falas em uma permanente relação com o cuidado à criança.

Trabalhar com a criança é provocar o encontro. Não só o encontro de pessoas, mas de culturas, de crenças e de modos de vida. (Betânia).

[...] cuidar pede para a compreensão do modo de vida das pessoas, das famílias, a cultura dessas famílias e as nossas também. Porque o mais difícil é esse choque entre a minha e a das famílias. E com a criança, com os cuidados a criança, principalmente dos recém-nascidos, temos muito para contar. Todos nós temos muitos relatos, o que significa que isso é muito presente. [...] Não sei se sabemos lidar bem com esses aspectos, tentamos. [...] as questões alimentares, os mingaus, o leite fraco, o peito que secou, o cuidado com o umbigo. São alguns exemplos que estão relacionados com a cultura, com os valores que as mães atribuem e que aprenderam na vida em família. (Claudia).

Nós fazemos um exercício para trazer para dentro da unidade essas experiências culturais da comunidade [...] essas experiências que as mães vivenciam lá fora. Conhecer as parteiras, as benzedeiras, as rezadeiras. [...] nos auxiliem no cuidado à criança. (Cecília).

Madeleine Leinninger, baseada em conhecimentos da antropologia, desenvolveu a Teoria Transcultural(13) ${ }^{(13)}$ cujo principal conceito é a cultura. Ao cuidar e observar crianças com transtornos mentais, a teórica, comparou comportamentos, estudou e determinou a importância e a influência da dimensão 
cultural no cuidado de enfermagem e em saúde. A partir daí, os seus escritos dirigiu-se a fundamentar o cuidado de enfermagem nos aspectos antropológicos. A cultura é constituída por valores, crenças, normas e práticas formadas por membros de um mesmo grupo social ${ }^{(14)}$. São valores que passam a guiar pensamentos e ações e são transmitidos de uma geração a outra. As crenças e práticas relacionadas à saúde são características da cultura ${ }^{(15)}$, determinam os modos de cuidar e de viver. São aspectos que desafiam o agir dos profissionais, que buscam meios e modos de cuidar e de lidar com essa dimensão no cotidiano do cuidado em saúde da criança. Os aspectos culturais "interfere no modo como o indivíduo se coloca no mundo e incluem o modo como ele promove a sua saúde e como busca caminho para a cura"(16).

As falas, acima apresentadas, demonstram que a cultura reflete nos modos da criança ser cuidada na família e na comunidade e, que, no cuidado à criança haverá sempre as marcas do saber cultural e do saber técnico-científico. As enfermeiras sujeitos de pesquisa relataram que aliam conhecimentos técnicos aos aspectos relacionais que o cuidado exige. Destacam as dimensões psicológicas, afetivas e sociais para valorizar a condição humana. Especificam como valores para o cuidar o respeito pelo outro e pela dignidade humana. Para elas esses valores são desenvolvidos no fazer cotidiano e é preciso ser exercitado.

\section{CONCLUSÃO}

Qualificando o Cuidado à Criança na Atenção Primária de Saúde, não é uma classificação linear do cuidado; apresentou-se como processo mutável e possível de ser reconstruído a cada encontro. Acreditamos que a saúde como ausência de doença é uma ideia superada, no entanto, a atenção à saúde nos seus aspectos subjetivos pressupõe transformações e requer, no cotidiano dos profissionais, sobretudo das equipes de saúde, uma postura ética, política e moral de reconhecimento da diferença da diversidade das demandas apresentadas pela população infantil, assim como as respostas oferecidas para solucioná-las.

O cuidado diferente, nesta investigação, é aquele em que a aproximação com a família se efetiva e onde as mães e as crianças são conhecidas pelo nome. O cuidado diferente é o cuidado amoroso, sensível, humano, solidário e terapêutico, que busca conciliar as várias dimensões da vida e do viver, aliando aos aspectos biológicos os sociais, culturais e psicológicos. A visita domiciliar pode se configurar como o que há de mais efetivo na relação de iguais. Na casa da família as relações são horizontalizadas, as mães se sentem importantes e seus esforços são reconhecidos pelos profissionais no cuidado diário aos seus filhos. $\mathrm{Na}$ casa da família, os profissionais percebem que apesar de todas as adversidades, como desemprego, precárias condições de moradia e saneamento, as mães se esforçam no cuidado preventivo e de promoção da saúde da criança.

O cuidado desigual parece ser um descuidado. No cuidado desigual as mães e as crianças são desconhecidas dos profissionais, tidas "como mais uma" e são responsabilizadas pela doença dos filhos. Vendo o cuidado diferente e Falando do Cuidado Desigual reforça a necessidade da clínica centrada nos sujeitos e em famílias reais onde as ações podem ser desenvolvidas pela utilização das tecnologias leves e na dimensão relacional. Compreendemos que uma ação realizada numa perspectiva médica técnico-científica não seja autenticamente de cuidado. É útil para a cura ou para reduzir os efeitos negativos da doença. Mas falta cuidar do agir e da atitude. É nesse contexto que se insere as práticas e os saberes dos profissionais e que precisam ser desafiados. Desafiados por um conhecimento que ultrapasse a fragmentação, pela perspectiva de saberes integradores, mutantes, capazes de combater as certezas e as racionalidades. $\mathrm{O}$ cuidado enquanto ato, meio e/ou produto de práticas em situação de saúde ou de doença é tarefa de todos, ou pelo menos deveria ser.

O cuidado não significa um procedimento que se encerra nele mesmo; o cuidado é o modo de estar em relação com o outro; significa valorizar o outro (alteridade); não é somente um encontro marcado pelo mecanismo de uma intervenção; o cuidado não aborda a doença, mas o individuo/sujeito portador de necessidades; o cuidado não se reduz à dimensão biológica - estende-se às dimensões subjetivas e sociais das crianças e suas famílias; no cuidado não há alienação - há interesse, escuta, olhares, toques, tato, comunicação, não há instrumentos padronizados - há incertezas e surpresas. Os diferentes modos de cuidar e de cuidado dão os contornos da atenção à criança na Atenção Primária de Saúde, onde profissionais e mães buscam novos modos de fazer: pelo cuidado diferente, pelo cuidado desigual, pelo cuidado integral e pelo movimento que acompanha as relações e os valores do cuidado, do cuidar e do ser humano. Afinal o cuidado deve mobilizar afetos, emoções, atenção.

Qualificando o cuidado à criança na Atenção Primária de Saúde é reconhecer que cuidar tem sentidos diferentes que se fundam no valor da vida e na dignidade humana. Compreendemos que o valor ao cuidado se constrói nos esforços, na colaboração, na comunicação, na complementaridade e no fazer/agir de profissionais, de famílias, de serviços e gestores. Qualificando o cuidado à criança é cuidado singular, é encontro que valoriza a vida e que respeita o outro nas suas diferenças. É atenção e responsabilidade pelo outro nas suas particularidades.

\section{REFERÊNCIAS}

1. Lessmann JC, Sousa FGM, Marcelino G, Erdmann AL. O olhar de acadêmicos de enfermagem acerca do ambiente de cuidado interpretado à luz do paradigma da complexidade. Online Braz J Nurs [periódico na internet]. 2005 [acesso em 13 maio 2006];5(1) Disponível em: < http://www. uff.br/objnursing/viewarticle.php?id $=249$ \&layout $=$ html $>$

2. Pinheiro R, Cecim RB. Experenciação, formação, cuidado e conhecimento em saúde: articulando concepções, percepções e sensações para efetivar o ensino da 
integralidade. In: Pinheiro R, Ceccim RB, Mattos RA, organizadores. Ensinar saúde: a integralidade e o SUS nos cursos de graduação na área da saúde. Rio de Janeiro: IMS/UERJ: CEPESQ; ABRASCO, 2006. p. 13-35.

3. Strauss $\mathrm{AL}$, Corbin J. Grounded Theory Methodology: an overview. In: Denzin NK, Lincoln YS. Handbook of quantitative research. Thousand Oaks: Sage Publications; 1994. p. 273-85.

4. Strauss AL, Corbin J. Pesquisa qualitativa: técnicas e procedimentos para o desenvolvimento de Teoria Fundamentada. Porto Alegre: Artmed; 2008

5. Waldow VR. Cuidar: expressão humanizadora da enfermagem. Petrópolis: Vozes; 2006.

6. Honoré B. Cuidar: persistir em conjunto na existência. Loures: Lusociência; 2004.

7. Rezende KTA. O processo de gerência nas unidades de saúde da família: limites e possibilidades em construção. Ribeirão Preto. Tese [Doutorado em Enfermagem]- Escola de Enfermagem, Universidade de São Paulo; 2007.

8. Ministério da Saúde, Secretaria de Atenção à Saúde, Departamento de Atenção Básica. Avaliação Normativa do PSF no Brasil: monitoramento da implantação e funcionamento das equipes saúde da família: 2001-2002/Secretaria de Atenção a Saúde. Departamento de Atenção Básica: Brasília; 2004.
9. Associação Brasileira de Enfermagem. Projeto de Classificação Internacional da Prática de Enfermagem em Saúde Coletiva no Brasil. Brasília: ABEn; 1996.

10. Conill EM. Políticas de atenção primária e reformas sanitárias: discutindo a avaliação a partir da análise do Programa de Saúde da Família em Florianópolis SC, Brasil, 1994 - 2000. Cad Saúde Pública 2002;18(Supl.):191-202.

11. Deslandes S. O cuidado humanizado como valor e ethos da prática em saúde. In: Pinheiro, Mattos RA, organizadores. Razões públicas para a integralidade em saúde: o cuidado como valor. Rio de Janeiro: CEPESC-IMS/UERJ-ABRASCO, 2007. p. 386-95.

12. Silva MJP. Comunicação tem remédio: a comunicação nas relações interpessoais. São Paulo: Loyola; 2002.

13. Leininger M. Culture care diversity and universality: a theory of nursing. New York: National League for nursing; 1991.

14. Giger JN, Davidhizar R. Transcultural Nursing Assessment Model. J Transcult Nurs 2002;13 (3):185-8.

15. Helman C. Cultura, saúde e doença. Porto Alegre: Artmed; 2003.

16. Cortez EA, Tocantins FR. Em busca de uma visão antropológica no Programa Saúde da Família. Rev Bras Enferm 2006;59(6):800-4. 